\title{
ADSORPTION AND THERMODYNAMICS PROPERTIES OF ACACIA TORTILIS AS CORROSION INHIBITOR OF ALUMINUM METAL MATRIX COMPOSITES IN ACIDIC MEDIUM
}

\author{
I. Y. Suleiman ${ }^{*}$, Rufai Suleiman Ochu ${ }^{2}$, A. A. Rasheed ${ }^{3}$, \\ O. C. Ogheneme ${ }^{4}$, O. S. Emokpaire \\ ${ }^{1}$ Department of Metallurgical and Materials Engineering, University of Nigeria, \\ Nsukka, Nigeria \\ ${ }^{2}$ Department of Chemistry, Ahmadu Bello University Zaria, Nigeria \\ ${ }^{3}$ National Agency for Science and Engineering Infrastructure, Abuja, Nigeria \\ ${ }^{4}$ Department of Mechanical Engineering, Waziri Umaru Federal Polytechnic, \\ Birnin Kebbi, Nigeria \\ ${ }^{5}$ Departmentof Metallurgical Engineering, Waziri Umaru Federal Polytechnic, \\ Birnin Kebbi, Nigeria
}

Received 20.05.2017

Accepted 29.06.2017

\begin{abstract}
Acacia tortilis (AT) was extracted and characterized by gas chromatographymass spectrometry (GC-MS). The eco-friendly corrosion inhibitor for aluminum matrix composites was investigated in $1.0 \mathrm{M} \mathrm{HCl}$ at $30-60{ }^{\circ} \mathrm{C}$. The concentration of the inhibitor and time were varied in the range of $0-10 \% \mathrm{v} / \mathrm{v}$ and $24-144 \mathrm{~h}$. The inhibition studies were carried out using gravimetric method and potentiodynamic polarization. The surface morphology of the coupons was characterized by SEM/EDS techniques. The GC-MS revealed some elements/compounds (NCS, C-H, N or O). The inhibition efficiency increased with concentration and decreased with increase in temperature. The optimum inhibition efficiency of $89.60 \%$ was obtained at concentration of $8 \% \mathrm{v} / \mathrm{v}$ at 30 ${ }^{\circ} \mathrm{C}$. Potentiodynamic polarization confirmed that the inhibitor acts as mixed types inhibitor. Activation energy $\left(E_{a}\right)$ with inhibitor was higher than without inhibitor and proved to be physisorption. The thermodynamic parameters (standard free energy $\Delta G^{\circ}$ ), standard enthalpy $\left(\Delta H_{a d s}\right)$ and standard entropy $(\Delta S)$ of the adsorption process were calculated. The inhibition mechanism of AT extract on $\mathrm{Al}-\mathrm{Si}-\mathrm{Fe} / 15 \% \mathrm{SiC}$ was physical and obeyed Langmuir adsorption isotherm. The protective layer on the composite surface confirmed the potential of the extract as corrosion inhibitor. The results of weight loss were in good agreement with those of electrochemical technique.
\end{abstract}

" Corresponding author: Yakubu Suleiman, onoruoizadnjumas@yahoo.co.uk 
Keywords: Acacia tortilis; Corrosion inhibition; Gravimetric method; Potentiodynamic polarization; SEM/EDS.

\section{Introduction}

Aluminum plays a key role in the development of metal matrix composites (MMCs) reinforced with a variety of ceramic materials including $\mathrm{Al}_{2} \mathrm{O}_{3}, \mathrm{TiC}, \mathrm{B}_{4} \mathrm{C}$, and $\mathrm{SiC}$. From the wide range of MMCs systems, considering their properties, $\mathrm{Al} / \mathrm{SiC}$ composites attracted the most attention of research scientists and technologists [1,2].

Aluminum matrix composites (AMCs) have received a considerable attention for military, automobile and aerospace applications because of their low density, high strength and high stiffness. The addition of ceramic reinforcements $(\mathrm{SiC})$ has raised the performance limits of the $\mathrm{Al}$ alloys. It is known that aluminum matrix composites exhibited better resistance to mechanical wear than their base alloys and hence they have specific strength for numerous weight sensitive applications [3].

One of the main disadvantages in the use of metal matrix composite is the influence of reinforcement on the corrosion rate. The addition of a reinforcing phase could lead to discontinuities in the matrix, thereby increasing the number of sites where corrosion can be initiated and thereby making the composites more susceptible to corrosion [4]. Numerous investigations have been devoted to study the corrosion behavior of $\mathrm{Al} / \mathrm{SiC}$ composites particularly in acid media and how it can be combated using inhibitors [5-10]. One of the methods to protect materials against corrosion is the use of inhibitor. Unluckily, many of the inhibitors used are inorganic salts or organic compounds with toxic properties such as borates and chromates. Because of awareness of ecological risks, attention has been drawn to find more suitable inhibitors which are non-toxic and environmentally friendly inhibitors [11]. Organic compounds containing both $\mathrm{O}, \mathrm{N}$ and $\mathrm{S}$ atoms appear as better adsorption inhibitors because of their lone pair of electrons and polar nature of the molecules. That is why these compounds had been investigated by researchers [12-17].

The present work aims at investigating the adsorption and thermodynamics properties of Acacia tortilis on the corrosion behavior of $\mathrm{Al}-\mathrm{Si}-\mathrm{Fe} / 15 \% \mathrm{SiC}$ in $1.0 \mathrm{M}$ $\mathrm{HCl}$ solutions at different concentration levels of the inhibitor as well as at different temperatures $\left(30-60{ }^{\circ} \mathrm{C}\right)$. The inhibition studies were carried out using gravimetric method and potentiodynamic polarization. The surface morphology of the coupons before and after corrosion tests were characterized by scanning electron microscopy (SEM) with Energy DispersiveX-ray Spectrometry (EDS) techniques.

\section{Experimental}

Preparation of the extract

The plant was sourced from Biological science garden, Ahmadu Bello University. The plant was cut into pieces, washed with water, dried at room temperature $\left(30{ }^{\circ} \mathrm{C}\right)$ and ground into powder. $100 \mathrm{~g}$ of the powder was refluxed in $100 \mathrm{ml}$ distilled water for $2 \mathrm{~h}$. Refluxed solution was then filtered and the filtrate was dissolved with 100 $\mathrm{ml}$ volume using double distilled water, representing the stock solution. The concentration of the stock solution is expressed in terms of $(\% \mathrm{v} / \mathrm{v})$. Thus, the concentration of $(2 \% \mathrm{v} / \mathrm{v}-10 \% \mathrm{v} / \mathrm{v})$ of the extract was prepared. 


\section{Gas chromatography-mass spectrometry (GC-MS)}

About $1 \mathrm{ml}$ of each concentration of the extract was analyzed by gas chromatography-mass spectrometry (GC-MS) using QP 2010 Plus Schmadzu product equipped with two fused-silica capillary columns $(60 \mathrm{~m} \times 0.22 \mathrm{~mm})$, film thickness, at National Research Institute for Chemical Technology (NARICT), Zaria. Analysis was performed under the following conditions: column oven temperature- $80{ }^{\circ} \mathrm{C}$; injection temperature- $250{ }^{\circ} \mathrm{C}$; injection mode- split flow; control mode- linear velocity; pressure$108.0 \mathrm{kPa}$; total flow- $6.2 \mathrm{ml} / \mathrm{min}$; column flow- $1.58 \mathrm{ml} / \mathrm{min}$; linear velocity- $46.3 \mathrm{~cm} / \mathrm{s}$; split ratio-1.0 [18].

\section{Preparation of specimens}

The test material in this work was $\mathrm{Al}-\mathrm{Si}-\mathrm{Fe} / 15 \% \mathrm{SiC}$ composite. The synthesis of the metal matrix composite used in this study was produced by the double stir-casting method at the Foundry Shop, Ahmadu Bello University, Zaria, Nigeria. The specimens were produced in dimension of $20 \mathrm{~mm}$ in diameter and $30 \mathrm{~mm}$ long. The compositions of the composite were presented in the Table 1.

Table 1. Composition of aluminum metal matrix composites (Al-Si-Fe/15\%SiC), wt. \%

\begin{tabular}{ccccccccc}
\hline Al & Si & Si C & Fe & Cu & Mg & Ni & Ti & Mn \\
\hline Bal & 7.00 & 15.00 & 1.00 & 0.008 & 0.48 & 0.007 & 0.079 & 0.004 \\
\hline
\end{tabular}

\section{Gravimetric Method}

The cast composite rods were mechanically cut into cylindrical shape of $20 \mathrm{~mm}$ by $10 \mathrm{~mm}$ with the surface area of $7.84 \mathrm{~cm}^{2}$. Before the experiment the coupons were abraded using emery papers (grades 200-1000) washed with distilled water and acetone and finally dried in an oven at $110{ }^{\circ} \mathrm{C}$. The initial weight of each specimen was measured before immersion using an analytical balance (Shimadzu Corporation, Model AUW120D). Then the specimens were immersed in aerated $(500 \mathrm{ml})$ of $1.0 \mathrm{M}$ of $\mathrm{HCl}$ solution without and with different concentrations of the Acacia tortilis extract for periods of 24, 48, 72, 96, 120 and $144 \mathrm{~h}$. Three coupons were withdrawn at the specific time, the surfaces were gently cleaned with iron brush to remove the corrosion products, weigh each coupon and take their average called weight loss (mg). From the data obtained, the corrosion rate (CR) and percentage of inhibition efficiency (\% I.E) were calculated using equations (1-2) [19].

$$
C R=\frac{87.6 W}{a t D}
$$

$\mathrm{CR}$ is defined as milimetre per year (mmpy), where, $\mathrm{W}$ is corrosion weight loss of composite (mg), $a$ is the area of the coupon $\left(\mathrm{cm}^{2}\right), \mathrm{t}$ is the exposure time in hours $(\mathrm{h})$ and $\mathrm{D}$ is the density of the composite $\left(\mathrm{g} \mathrm{cm}^{-3}\right)$.

$$
I E \%=\frac{C R_{a}}{C R_{p}} \times 100
$$

where: $C R_{a}$ and $C R_{p}$ are corrosion rates in the absence and presence of inhibitor, respectively. 


\section{PotentiodynamicPolarization}

The specimens were embedded in epoxy resin leaving a working area of 1.33 $\mathrm{cm}^{2}$. The working surface was subsequently ground with 600 and 1800 grit grinding papers, cleaned by distilled water and ethanol. The solutions $(1.0 \mathrm{M} \mathrm{HCl})$ were prepared from analytical reagent. Potentiodynamic polarization measurements were done using an Autolab potentiostat (PGSTAT30 computer controlled) with the General Purpose Electrochemical Software (GPES) package version 4.9. Anodic and cathodic polarization curves were obtained with a scan rate of $2 \mathrm{mv} / \mathrm{s}$ in the potential range from $-0.2 \mathrm{mv}$ to $-0.8 \mathrm{mv}$ relative to the corrosion potential $\left(E_{\text {corr }}\right)$. Values of the corrosion current density $\left(i_{c o r r}\right)$ were obtained by extrapolation of the cathodic branch of the polarization curve back to $E_{\text {corr }}$. The Tafel slopes, corrosion potential and corrosion current were calculated using Frequency Response Analyzer (FRA). All tests were performed at temperature of $30{ }^{\circ} \mathrm{C}$. The inhibitor efficiency was calculated from equation 3 according to [20].

$$
I E \%=\frac{i_{\text {corr }}-i_{\text {corr }}^{\prime}}{i_{\text {corr }}} \times 100 \%
$$

where: $i_{\text {corr }}$ and $i_{\text {corr }}^{\prime}$ are the corrosion current densities of the composites in the absence and presence of the inhibitor, respectively.

\section{Surface analysis}

Surface examination of the composite specimens in the absence and presence of the optimum concentration of the extract immersed at $30{ }^{\circ} \mathrm{C}$ were studied using a Philips model XL30SFEG scanning electron microscope (SEM) attached with energydispersive X-ray spectroscopy (EDS) and having the magnification of 2000X.

\section{Results and Discussion}

\section{Gravimetric Method}

The gravimetric weight loss studies were carried out in 1.0M hydrochloric acid in the absence and presence of various concentrations of the plant extracts ranging from 2 to $10 \% \mathrm{v} / \mathrm{v}$. The corrosion parameters such as corrosion rate, inhibition efficiency, surface coverage and the optimum concentration of the extract are presented in Table 2 and illustrated in Figures 1 and 2. From Table 2, it was found that with the addition of the plant extract to $1.0 \mathrm{M} \mathrm{HCl}$ decreased corrosion rate while the inhibition efficiency was increased. The optimum concentration for Acacia tortilis (AT) was found to be $8 \%$ $\mathrm{v} / \mathrm{v}$ with maximum inhibition efficiency of $89.60 \%$, for a period of $72 \mathrm{~h}$ of immersion time. This result indicated that the plant extract acted as an effective corrosion inhibitor for the composites in 1.0M HCl. Similar results were obtained and published in literature [21], in which plant extract was used to inhibit mild steel in acidic media. 
Suleiman et al. - Adsorption and thermodynamics properties of acacia tortilis as corrosion ... 157

Table 2. Values of corrosion rate and inhibition efficiency from weight loss of $\mathrm{Al}-\mathrm{Si}-\mathrm{Fe} / \mathrm{SiC}$ at 30, 40, 50 and $60^{\circ} \mathrm{C}$

\begin{tabular}{ccccccccc}
\hline & \multicolumn{8}{c}{ Corrosion Rate (mmpy) } \\
\cline { 2 - 9 } $\begin{array}{c}\text { Ext. } \\
(\text { \% v/v) }\end{array}$ & $\mathbf{3 0 3 K}$ & $\mathbf{3 1 3 K}$ & $\mathbf{3 2 3 K}$ & $\mathbf{3 3 3 K}$ & $\mathbf{3 0 3 K}$ & $\mathbf{3 1 3 K}$ & $\mathbf{3 2 3 K}$ & $\mathbf{3 3 3 K}$ \\
\cline { 2 - 9 } Blank & 20.671 & 24.650 & 29.561 & 31.890 & - & - & - & - \\
2 & 6.430 & 8.434 & 10.742 & 12.507 & 68.89 & 65.79 & 63.66 & 60.78 \\
4 & 5.289 & 7.230 & 8.871 & 10.932 & 74.41 & 70.67 & 69.99 & 65.72 \\
6 & 2.313 & 3.989 & 5.779 & 7.708 & 88.81 & 83.82 & 80.45 & 75.83 \\
8 & 2.145 & 2.564 & 5.368 & 7.159 & 89.68 & 84.77 & 81.84 & 77.55 \\
10 & 2.156 & 3.946 & 5.723 & 7.344 & 89.57 & 83.99 & 80.64 & 76.97 \\
\hline
\end{tabular}

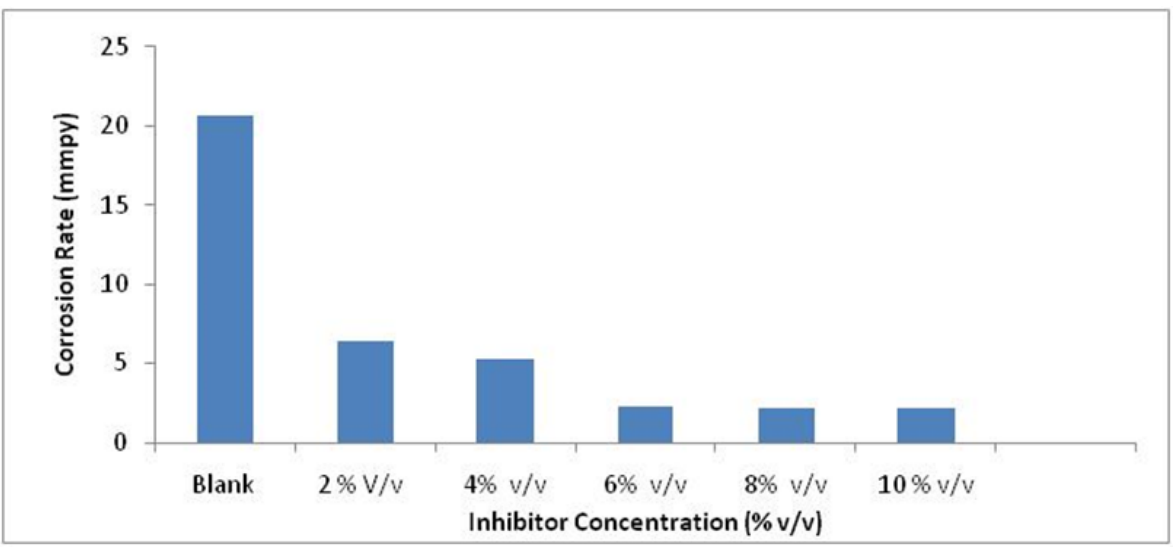

Fig. 1. Corrosion rate of 1.OM HCl of Al-Si-Fe/SiC in the presence of Acacia tortilis against concentration after 144 hours of exposure at $30^{\circ} \mathrm{C}$.

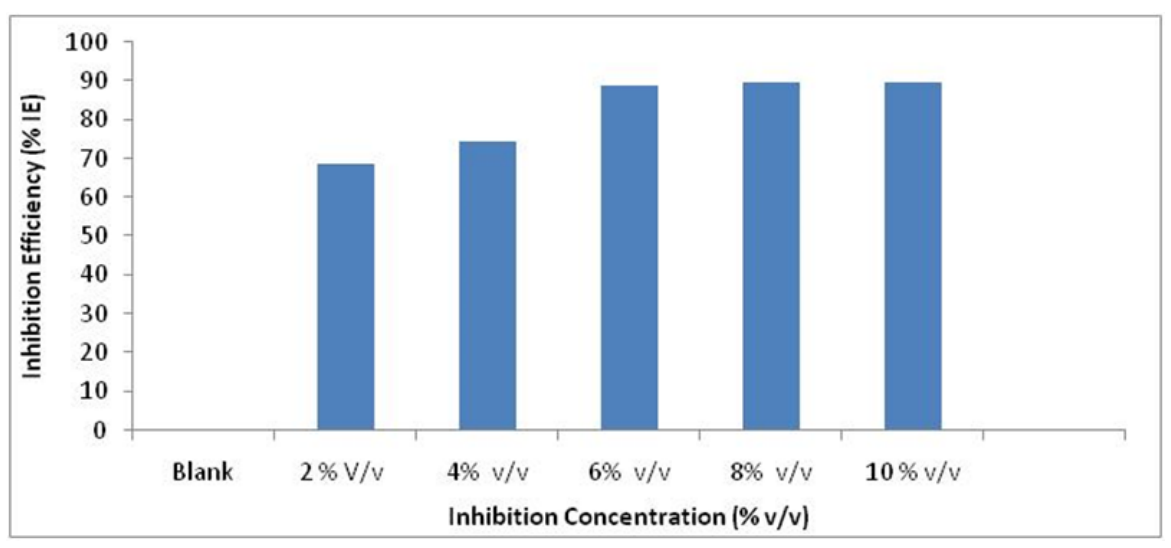

Fig. 2. Inhibition efficiency of 1.0 M HCl of Al-Si-Fe/SiC in the presence of Acacia tortilis against concentration after 144 hours of exposure at $30^{\circ} \mathrm{C}$. 
The decrease in inhibition efficiency with increasing temperature may be attributed to a possible shift of the adsorption/desorption of equilibrium towards desorption of adsorbed inhibitor due to increasing solution agitation [22]. Thus, as the temperature increases, the number of adsorbed molecules decreased leading to a decrease in the inhibition efficiency. This indicates that the extract of Acacia tortilis functional groups tend to dissociates at higher temperatures and became ineffective inhibitor. Desorption of the inhibitor constituents at higher temperatures was noted by authors [23], which resulted to higher corrosion rates.

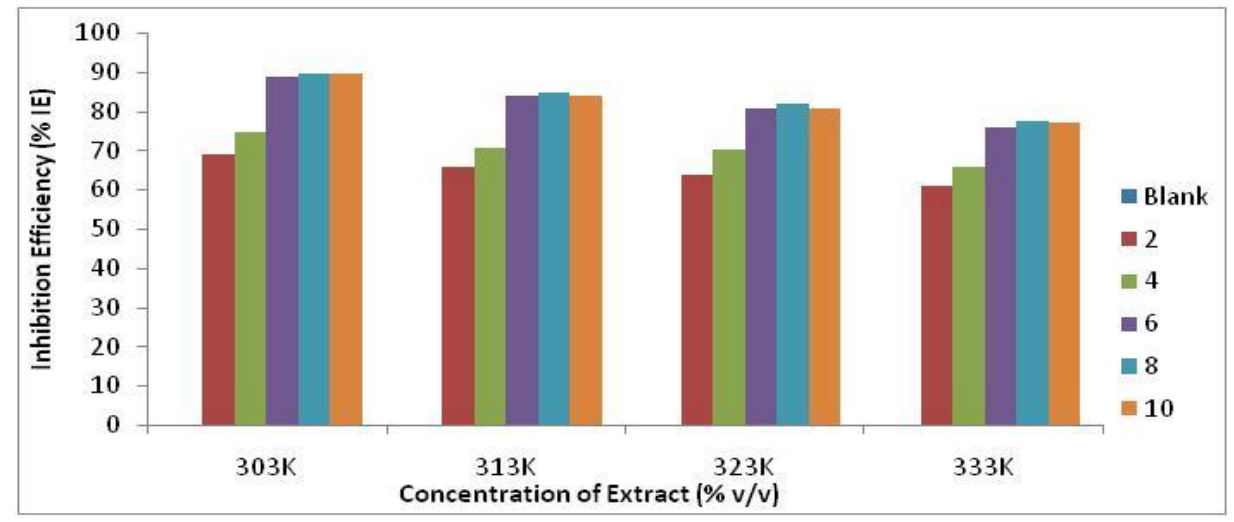

Fig. 3. Variation of inhibitor efficiency (IE \%) with immersion temperature at different immersion time for $8 \% \mathrm{v} / \mathrm{v}$ of Acacia tortilis inhibitor concentration.

\section{Effect of immersion time}

The effect of immersion time from $24 \mathrm{~h}$ to $144 \mathrm{~h}$ on inhibition efficiency was studied and presented in Figure 4 and Table 3 . The inhibition efficiency was found to decrease from $89.60 \%$ at $72 \mathrm{~h}$ to $86.45 \%$ at $144 \mathrm{~h}$ when immersion time was increased due to desorption of adsorbed process with time.

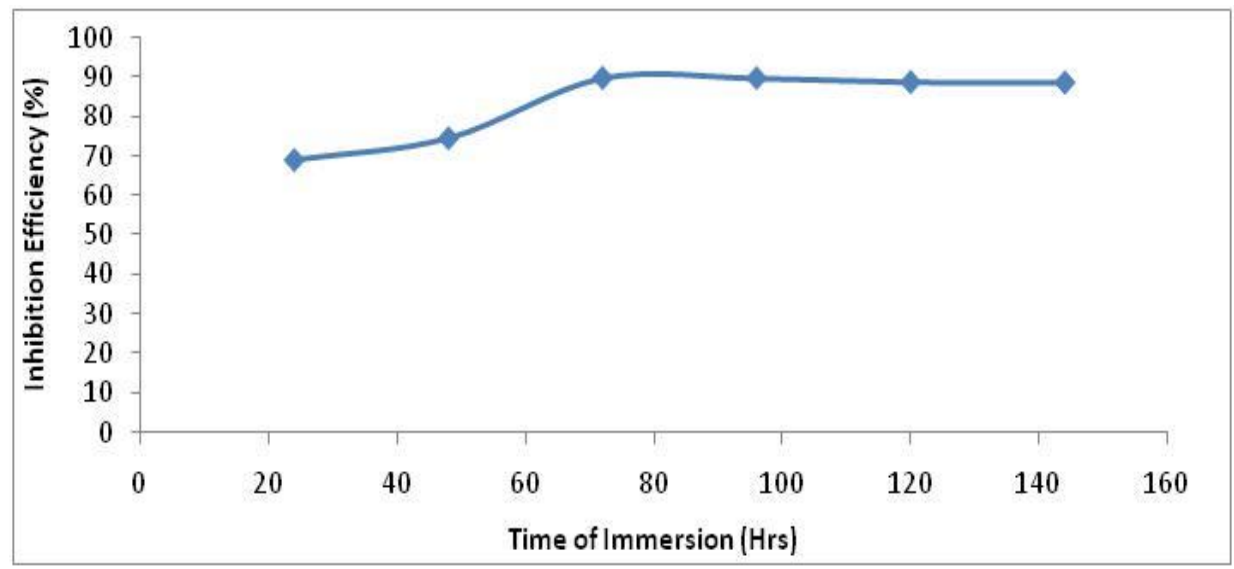

Fig. 4. Variation of inhibition efficiency of Acacia tortilis extract in 1.OM HCl with immersion time of the solution 
Suleiman et al. - Adsorption and thermodynamics properties of acacia tortilis as corrosion ... 159

Table 3. Effect of immersion time on percentage of inhibition efficiency of Al-Si-Fe/SiC in $1.0 \mathrm{M} \mathrm{HCl}$ at $30^{\circ} \mathrm{C}$ in the presence of optimum concentrations of the plant extracts

\begin{tabular}{|c|c|c|c|c|c|c|}
\hline \multirow{3}{*}{$\begin{array}{l}\text { Name of the plant extract } \\
\text { with optimum } \\
\text { concentrations }\end{array}$} & \multicolumn{6}{|c|}{ Inhibition efficiency (IE \%) } \\
\hline & \multicolumn{6}{|c|}{ Immersion time $(\mathrm{h})$} \\
\hline & 24 & 48 & 72 & 96 & 120 & 144 \\
\hline $8 \% \mathrm{v} / \mathrm{v}$ Acacia tortilis $(A T)$ & 68.89 & 74.41 & 89.60 & 89.57 & 88.58 & 88.45 \\
\hline
\end{tabular}

\section{Potentiodynamic polarization curves}

Potentiodynamic polarization parameters obtained for different concentrations of the plant extract are given in Table 4 and the polarization curves are illustrated in Figure 5. Potentiodynamic polarization studies revealed that the corrosion current density (Icorr) markedly decreased with the addition of the extract and the corrosion potential shifts to less negative values upon addition of the plant extract. However, the values of anodic and cathodic Tafel slopes were changed indicating that this behavior reflects the plant extract ability to inhibit the corrosion of composite in $1.0 \mathrm{M} \mathrm{HCl}$ solution via the adsorption of its molecules on both anodic and cathodic sites. The behavior reflects the plant extract ability to inhibit the corrosion of composite $1.0 \mathrm{M} \mathrm{HCl}$ solution through the adsorption of its molecules on both anodic and cathodic sites [24]. It was observed that with increase in concentration of the plant extract from $2 \%$ to $10 \%$, the maximum inhibition efficiency of $89.91 \%$ was observed for Acacia tortilis extract at $8 \% \mathrm{v} / \mathrm{v}$ of the extract.

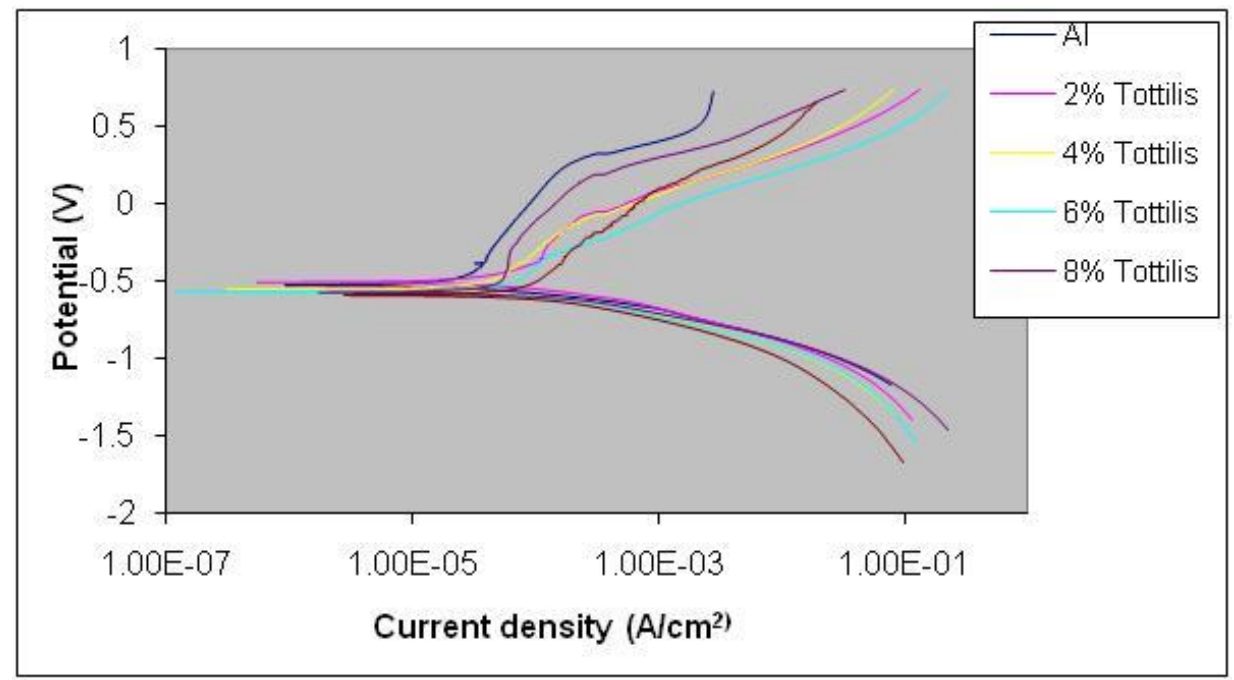

Fig. 5. Potentiodynamic polarization curves of composites in $1.0 \mathrm{M} \mathrm{HCl}$ solution in the absence and presence of various concentrations of the plant extract AS at $30{ }^{\circ} \mathrm{C}$. 
Table 4. Potentiodynamic polarization parameters of Al-Si-Fe/SiC composites in $1.0 \mathrm{M}$ $\mathrm{HCl}$ containing different concentrations of AT extract at $30^{\circ} \mathrm{C}$

\begin{tabular}{cccc}
\hline Conc. of extract $(\% \mathbf{v} / \mathbf{v})$ & $\boldsymbol{E c o r r} / \mathbf{V}$ & $\boldsymbol{I c o r r} /\left(\mathbf{m A} / \mathbf{c m}^{\mathbf{2}}\right)$ & Inhibition efficiency (\%) \\
\hline 0 & -0.521 & 0.369 & - \\
2.0 & -0.547 & 0.115 & 68.89 \\
4.0 & -0.555 & 0.094 & 74.61 \\
6.0 & -0.569 & 0.041 & 88.81 \\
8.0 & -0.550 & 0.041 & 89.91 \\
10.0 & -0.593 & 0.039 & 89.57
\end{tabular}

\section{Adsorption Isotherms}

Adsorption of Acacia tortilis (AT) on the Al-Si-Fe/SiC surface and the interaction between them can be described by adsorption isotherms. The corrosion rates obtained were tested graphically by fitting into various isotherms such as: El-Awady, Freundlich, Frumkin, Temkin and Langmuir models as described elsewhere [34-36] and shown in equation 5 .

$$
\frac{\theta}{1-\theta}=K_{a d s} C
$$

where: $K_{a d s}$ is the equilibrium constant of the inhibitor adsorption process and C is the inhibitor concentration in the solution. A straight line was obtained on plotting $\mathrm{C} / \theta$ against $\mathrm{C}$ presented in Figure 6 suggesting that the adsorption of the compound on composite surface follows Langmuir adsorption isotherm model. These results show that all the linear correlation coefficients $\left(\mathrm{R}^{2}\right)$ are almost equal to unity and all the slopes slightly deviated from unity. However, Langmuir isotherm assumes that the metal surface contains a fixed number of adsorption sites and each site holds one adsorbate, $\Delta G_{a d s}$ is the same for all sites and it is independent of $\theta$ and finally the adsorbates do not interact with one another, i.e. there is no effect of lateral interaction of the adsorbates as observed by [25]. The free energy of adsorption is related to the equilibrium constant of adsorption, $K_{a d s}$ by the following equation:

$$
\Delta G_{a d s}=-R T \ln \left(55.5 K_{a d s}\right)
$$

The values of free energy of adsorption $\left(\Delta G_{a d s}\right), K_{a d s}$, slope and $\mathrm{R}^{2}$ for Acacia tortilis in the temperature range of $30-60{ }^{\circ} \mathrm{C}$ were shown in Table 5 . The values of equilibrium constant $\left(K_{a d s}\right)$ are relatively small, and decrease with increase in temperature suggesting that the interaction between the adsorbed extract molecules and $\mathrm{Al}-\mathrm{Si}-\mathrm{Fe} / \mathrm{SiC}$ surface was adsorbed physically [8]. The negative values of $\Delta G_{a d s}$ obtained from equation 6 showed the spontaneity of the adsorption process and the stability of the adsorbed layer on the composite surface. The equilibrium constant of adsorption, $K_{a d s}$, can be used to describe the strength of binding between the metal and inhibitor. The obtained value of $K_{a d s}$ decreases with increase in temperature which implies that the binding strength weakens with increase in temperature - possibility of desorption of inhibitor molecules. This trend coupled with values of $\Delta G_{a d s}$ is less negative than $-40 \mathrm{kJmol}^{-1}$ has been associated with spontaneous physical adsorption mechanism as observed in literature [26]. 


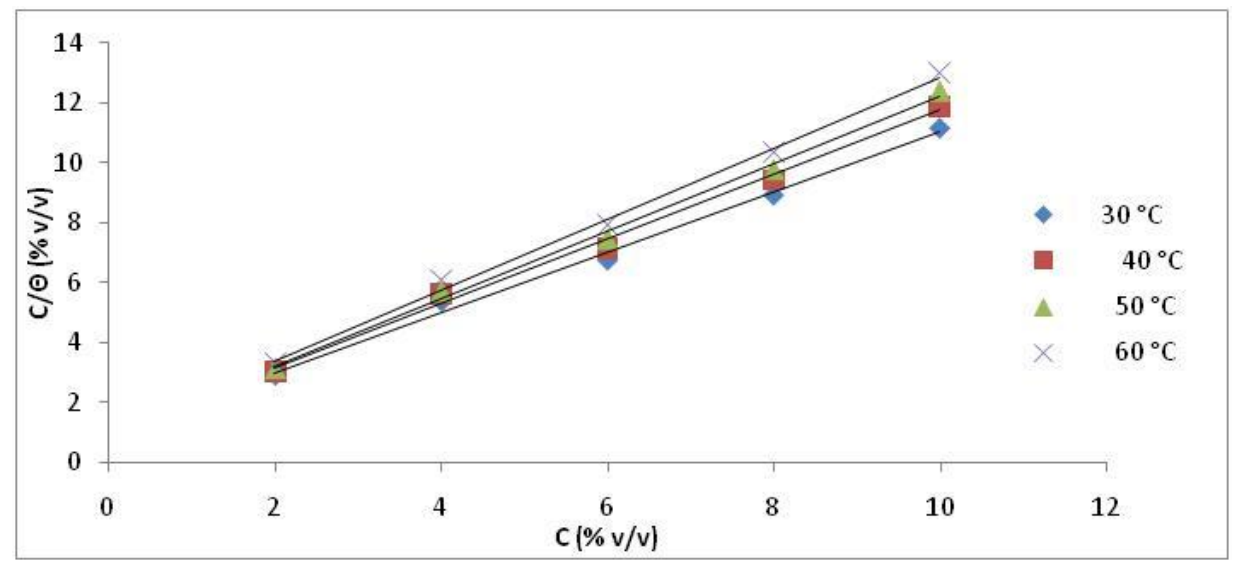

Fig. 6. Langmuir adsorption isotherm for the adsorption of the AT inhibitor on the Al$\mathrm{Si}$ - Fe/SiC surface in $1.0 \mathrm{M} \mathrm{HCl}$ solution by gravimetric method at 30, 40, 50 and $60^{\circ} \mathrm{C}$

Table 5. Parameters from Langmuir Isotherm for AT at 30, 40, 50 and $60{ }^{\circ} \mathrm{C}$ in $1.0 \mathrm{M}$ $\mathrm{HCl}$ solution

\begin{tabular}{lclll}
\hline Temp. & \multicolumn{4}{c}{ Langmuir isotherm } \\
\hline$\left({ }^{\circ} \mathbf{C}\right)$ & $\Delta \boldsymbol{G}_{\text {ads }}(\mathbf{K J} / \mathbf{m o l})$ & Slope & $\mathbf{R}^{\mathbf{2}}$ & $\boldsymbol{K}_{\text {ads }}$ \\
\hline 30 & 11.485 & 1.003 & 0.994 & 1.078 \\
40 & 9.510 & 1.075 & 0.994 & 0.6958 \\
50 & 9.246 & 1.128 & 0.996 & 0.5633 \\
60 & 8.796 & 1.181 & 0.996 & 0.4318 \\
\hline
\end{tabular}

\section{Effect of temperature}

The corrosion rates increase with increase in temperature from 30 to $60{ }^{\circ} \mathrm{C}$. To describe the effect of temperature on the corrosion inhibition process, the corrosion rates obtained from the weight loss were fitted into Arrhenius kinetic model illustrated in Figure 7 according to equation 7. The calculate activation parameters were presented in Table 6. The obtained activation energy was higher in the inhibited solution than the free acid solution. The activation energy being the energy barrier that molecule of the free acid must possess in order to attack and corrode the composite surface. This barrier was found to be higher in the presence of the inhibitor which implies that introduction of the Acacia tortilis deepens the location of the aluminum ions in the composite, requiring more energy to cross over and become cations as noted in [27] and resulted to high inhibition efficiency and hence protecting the composite. [28]:

The log of corrosion rate is a linear function of temperature (Arrhenius equation)

$\log C R=\log A-E a / 2.303 R T$

where: Ea is the apparent effective activation energy, $\mathrm{R}$ is the general gas constant and $\mathrm{A}$ is Arrhenius pre-exponential factor. A plot of $\log$ of corrosion rate 
obtained by weight loss measurement versus $1 / \mathrm{T}$ gave a straight line with a slope of $\mathrm{Ea} / 2.303 R$.

An alternative formulation of Arrhenius equation given in equation 8 was used to calculate the $\Delta H_{a d s}$ and $\Delta S_{a d s}$ as given by [28]:

$$
C R=\frac{R T}{N h} \exp \left(\frac{\Delta S}{R}\right) \exp \left(\frac{\Delta H}{R T}\right)
$$

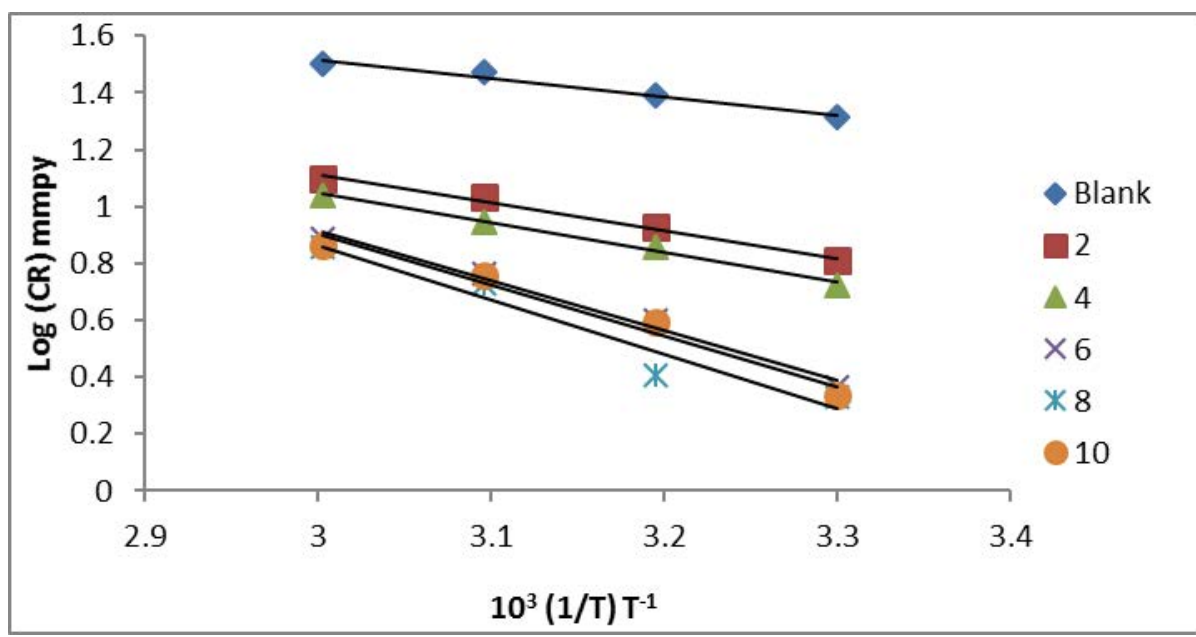

Fig.7.Variation log CR with 1/T for Al-Si-Fe/SiC in $1.0 \mathrm{M} \mathrm{HCl}$ in the absence and presence of $A T$ concentrations at $30,40,50$ and $60^{\circ} \mathrm{C}$.

where: $\mathrm{CR}$ is the corrosion rate of composite, $\mathrm{R}$ is the gas constant, $\mathrm{N}$ is the Avogadro's number $(6.022 \times 1023 \mathrm{~mol}), \mathrm{h}$ is the Planck constant $(6.6261 \times 10-34 \mathrm{Js}), \mathrm{T}$ is the temperature, $\Delta S_{a d s}$ and $\Delta H_{a d s}$ are the entropy and enthalpy of adsorption of the inhibitor on composite surface, respectively. Transforming (eqn. 8) into a linear form by taking the logarithm of both sides [29] gives equation 9:

$$
\log (C R / T)=\log (R / N h)+\Delta S_{a d s} / 2.303 R-\Delta H_{a d s} / 2.303 R T
$$

From equation 9, a plot of $\log (\mathrm{CR} / \mathrm{T})$ versus $1 / \mathrm{T}$ is expected to yield a straight line with slope and intercept equal to $\Delta \mathrm{H}_{\mathrm{ads}} / 2.303 \mathrm{R}$ and $\left(\log (\mathrm{R} / \mathrm{Nh})+\Delta \mathrm{S}_{\mathrm{ads}} / 2.303 \mathrm{R}\right)$ is illustrated in Figure 8. The values of activation energy, enthalpy and entropy (Ea, $\Delta H_{a d s}$, $\Delta S_{a d s}$ ) obtained for the extract in $1.0 \mathrm{M}$ in $\mathrm{HCl}$ were shown in Table 6 . The negative values of $\Delta H_{a d s}$ obtained in the case of the adsorption of $A T$ on the composite indicates a decrease of the degree of surface coverage with rise in temperature, supporting the earlier proposed physisorption mechanism [30]. The value of $\Delta S_{a d s}$ in the presence of $A S$ is negative, meaning that a decrease in disordering takes place going from reactants to the metal adsorbed species reaction complex [31]. 


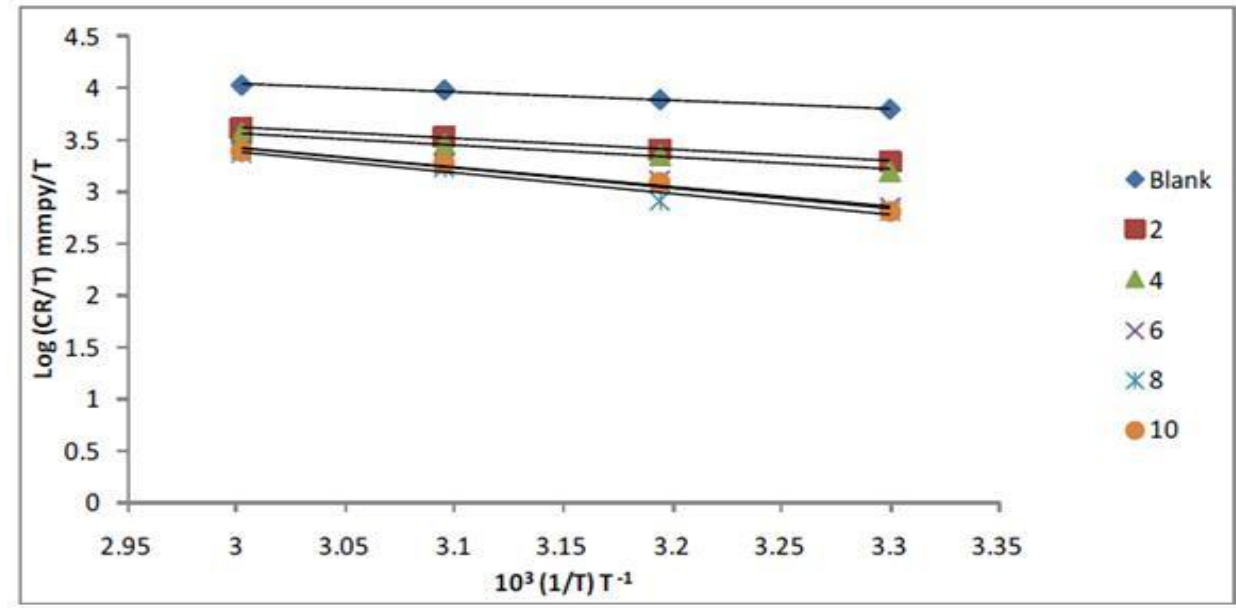

Fig. 8. Variation of $\log C R / T$ with $1 / T$ for Al-Si-Fe/SiC in $1.0 \mathrm{M} \mathrm{HCl}$ in the absence and presence of AT concentration at $30,40,50$ and $60^{\circ} \mathrm{C}$.

Table 6. Activation parameters Ea, $\Delta H_{\text {ads }}$ and $\Delta S_{\text {ads }}$ of Al-Si-Fe/SiC dissolution in 1.0 $\mathrm{M} \mathrm{HCl}$ in the absence and presence of AT at 30,40, 50 and $60^{\circ} \mathrm{C}$

\begin{tabular}{lccc}
\hline Concentration & $\mathbf{E a}(\mathbf{K J} / \mathbf{m o l})$ & $\Delta \boldsymbol{H}_{\boldsymbol{a d s}},(\mathbf{J} / \mathbf{m o l})$ & $-\Delta \boldsymbol{S}_{\boldsymbol{a d s}},(\mathbf{K J} \mathbf{J} \mathbf{m o l})$ \\
\hline Blank & 12.48 & 15.11 & 74.86 \\
$2 \% \mathrm{v} / \mathrm{v}$ & 18.82 & 21.46 & 63.60 \\
$4 \% \mathrm{v} / \mathrm{v}$ & 20.03 & 22.67 & 61.19 \\
$6 \% \mathrm{v} / \mathrm{v}$ & 33.07 & 36.17 & 23.28 \\
$8 \% \mathrm{v} / \mathrm{v}$ & 36.46 & 39.08 & 15.47 \\
$10 \% \mathrm{v} / \mathrm{v}$ & 37.14 & 41.76 & 21.65 \\
\hline
\end{tabular}

Surface Examination Studies

Figures 9-11 show the results of different structure morphologies of coupons of composites, polished without and with Acacia tortilis. The morphology of the uninhibited surface was altered during corrosion and as expected it was rough, uneven surface covered, pits and cracks were seen in Figure 10. However, no pits and cracks were observed in the morphology of sample with inhibitor as indicated in Figure 11. The protective film formed on the surface of the composite was confirmed by scanning electron microscopy (SEM) studies. In the presence of the optimum extract, composite immersed in acidic medium-plant extract indicated a protective film and smooth surfaces as noted with earlier work [32-34]. 

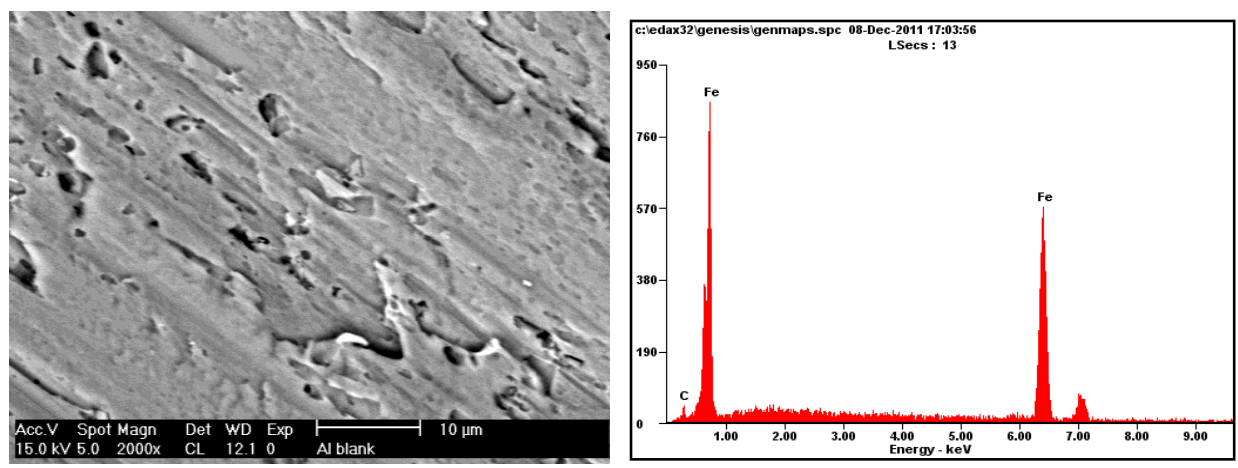

Fig. 9.SEM/EDS microstructure of aluminum composite as-received.
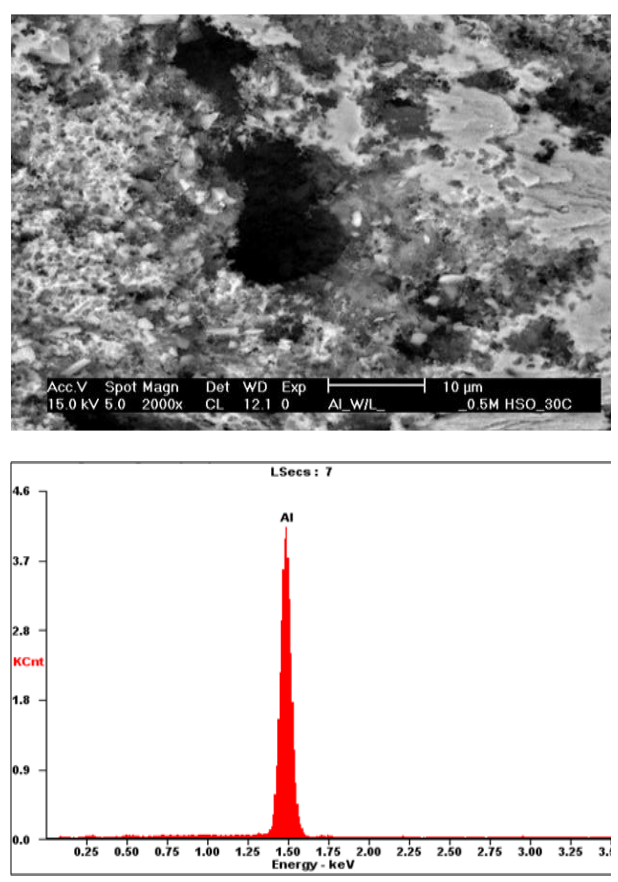

Fig. 10. SEM microstructure and EDS spectrum of composite immersed in $1.0 \mathrm{M} \mathrm{HCl} \mathrm{at}$ $30{ }^{\circ} \mathrm{C}$ without extract (control). 

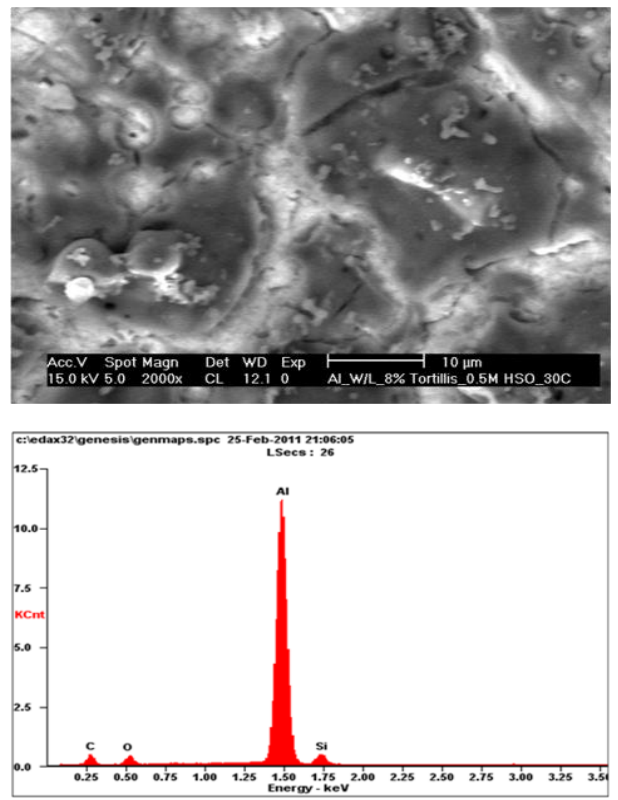

Fig. 11. SEM microstructure and EDS spectrum of composite immersed in $1.0 \mathrm{M} \mathrm{HCl} \mathrm{at}$ $30{ }^{\circ} \mathrm{C}$ with extract.

\section{Conclusion}

From the results and discussion, the following conclusions can be drawn:

1. The Acacia tortilis offered good inhibitive effectiveness at lower temperatures, but became less effective as temperature increased.

2. Acacia tortilis (AT) acts as good inhibitor for the corrosion of aluminum composite in $1.0 \mathrm{M} \mathrm{HCl}$ solution.

3. The optimum inhibition efficiency was $89.60 \%$ at $8 \% \mathrm{v} / \mathrm{v}$, at $30{ }^{\circ} \mathrm{C}$ and decreased to $77.55 \%$ at $60{ }^{\circ} \mathrm{C}$.

4. The adsorption of Acacia tortilis on composite surface is spontaneous and involves physical adsorption mechanism.

\section{References}

[1] G. M. Pinto, J. Nayak, N. Shetty: J Min Met Mat Sci, 21 (2011) 53-71

[2] J. A. Aguilar-Martínez, M. I. Pech-Canul, M. Rodríguez-Reyes, J. L. De La Pena: J Mater Sci, 39 (2004) 1025-1028.

[3] Z. Ahmad, P. T. Paulette, B. J. A. Aleem: J Mater Sci, 35 (2000) 2573-2579.

[4] Y. Cui: Key Eng Mat, 249 (2003) $45-48$.

[5] A. J. Trowsdate, B. Noble, S. J. Haris, I. S. R. Gibbins, G. E. Thomson, G. C. Wood: Corros Sci, 38 (1996) 177-187.

[6] A. Pardo, M. C. Merino, S. Merino, F. Viejo, M. Carboneras, R. Arrabal: Corros Sci, 47(2005) 1750-1764.

[7] J. B. Bessone, D. R. C. Salinas, M. Mayer Ebert, W. J. Lorenz: Electrochim Acta, 37 (1992) 2283-2290. 
[8] T. David, T. James: Corrosion science and technology, CRC Press, Florida, p.127 (1998).

[9] I. Y. Suleiman, S. A. Yaro, M. Abdulwahab: Asian J Chem, 28 (2016) 242-248.

[10] N. Chawla, Y. Shen: Adv Eng Mat, 3 (2001) 357-370.

[11]D. Lloyd: J Int Mats, 39 (1999) 1-9.

[12] J. Guo, X. Yuan: Mater Sci and Eng A, 499 (2009) 212-214.

[13]M. K. Surappa, Aluminium matrix composites: challenges and opportunities, Sadhana 28 (2003) 319-334.

[14] C. K. Kim, S. Y. Park: J Korean Inst Met Mater, 22 (1984) 125-92.

[15] K. K. Alaneme, M.O. Bodunrin: J Min and Mat Character and Eng, 10 (2011) 1153-1165.

[16] G. B. Veeresh Kumar, C. S. P. Rao, N. Selvaraj: J Miner Mater Charac Eng, 10 (2011) 59-91.

[17]V. S. Sastri, Chemical aspects of corrosion inhibition, Principles and Application, John Wiley \& Sons Press, England, p. 99 (1998).

[18]P. R.Vijayalakshmi, R. Rajalakshmi, S. Subhashini: Port Electrochim Acta, 29 (2011) 9-21.

[19]F. Asuke, S. A. Yaro, O. B. Oloche: J Appl Sci Res, 6 (2010) 1759-1765.

[20] O. B. Oloche, S. A. Yaro, E. G. Okafor: J Alloy Compd, 472 (2009) 178 -185.

[21]P. P. Trzaskoma: Corros Sci, 46 (1990) 402-409.

[22]E. E. Ebenso, A. Hailemichael, S. A. Umoren, I. B Obot: Int J Electrochem Sci, 3 (2008) 1325-1339.

[23] A. M. Al-Turkustani, S. T. Arab, R. H. Al-Dahiri: Mod Appl Sci, 4 (2010) 105124.

[24] S. Candan, E. Bilgic: Mats lett 58 (2004) 2787-2790.

[25]E. E. Ebenso, U. J. Ibok, Ekpe, S. A. Umorens, E. Jackson, O. K. Abiola, N. C. Oforka, S. Martinez: Trans Saest, 39 (2004)117-123.

[26] E. E. Ebenso, U. J Ekpe, S. A. Umoren, E. Jackson, O. K. Abiola, N. C. Oforka: J Appl Poly Sci, 100 (2006) 2889 -2894.

[27] A. A. Al-Sarawy, F. Sh. Ahmed, H. M. El-Abbasy: Corros Sci, 51 (2009) 485-492.

[28] I. B. Obot, S. A. Umoren, N. O. Obi-Egbedi: Mats Environ Sci, 2 (2011) 60-71.

[29] S.J. Zakvi, G.N.Mehta: J Electrochem Soc India, 37 (1988) 237-239.

[30]E. E. Oguzie: Port Electrochimi Acta, 26 (2008) 303-314.

[31] M. H. Hussin, M. J. Kassim: J Phys Sci, 21 (2010) 1-13.

[32] A. Ostovari, S. M. Hoseinieh, M. Peikari, S. R. Shadizadeh, S. J. Hashemi: Corros Sci, 51, (2009) 1935-1949.

[33] A. P. I. Popoola, M. Abdulwahab, O. S. Fayomi: Int J Electrochem Sci,7 (2012) $5805-5815$.

[34] S. A. Abd El-Maksoud: Int J Electrochem Sci, 3 (2008) 528-555. 